\title{
The effect of knowledge on uptake of breast cancer prevention modalities among women in Kyadondo County, Uganda
}

\author{
Christine Atuhairwe ${ }^{1}$, Dinah Amongin ${ }^{1}$, Elly Agaba ${ }^{2}$, Steven Mugarura ${ }^{1}$ and Ivan M. Taremwa ${ }^{1 *}$
}

\begin{abstract}
Background: Breast cancer, the third most frequent cancer of women is preventable through knowledge on breast self-examination. Of the $44 \%$ of women diagnosed with breast cancer at the Uganda Cancer Institute, only 22\% go for check-up in less than three months. This study explored the effect of breast cancer knowledge on the uptake of breast cancer prevention modalities among women in Kyadondo County, Uganda.

Methods: A household survey of women in Kyadondo County was conducted during June, 2014 to August, 2015. This involved studying in-depth using a questionnaire the level of breast cancer knowledge of the respondents. Data was analyzed using logistic regression model. Chi-square test was used to establish relationships between knowledge base factors and the uptake of breast cancer prevention modalities.

Results: This study has established an empirical relationship between uptake of breast cancer prevention modalities and source of information especially radio (OR 1.94 95\% Cl: 1.16-3.24), television (OR 1.82 95\%Cl: 1.14-2.93), awareness of breast cancer (OR 4.03 95\%Cl: 1.01-15.98), knowledge on how to reduce risk of breast cancer (OR 1.98 95\% Cl: 1.20-3.27), what reduces breast cancer acquisition (OR 2.75 95\% Cl: 1.42-5.35), how to check for signs of breast cancer especially through breast self-examination (OR 3.09 95\% Cl: 1.62-5.88), and other methods of breast cancer diagnosis in a health care set up.
\end{abstract}

Conclusion: The women's level of breast cancer awareness as a primary prevention strategy was found wanting, and requires a boost through community health education.

Keywords: Knowledge, Breast cancer, Modalities, Prevention, Uganda

\section{Background}

Breast cancer is the third commonest cancer after cervical cancer and Kaposi sarcoma [1-4]. Worldwide, breast cancer remains the most frequently diagnosed cancer and the leading cause of cancer death among females accounting for $23 \%$ of the total cancer cases and $14 \%$ of the cancer deaths with a $3 \%$ annual incidence and $1.8 \%$ death rate $[3,4]$. In Uganda is estimated at $4.5 \%$ annually as per the age standardized incidence rate but is curable if promptly diagnosed through breast selfexamination (BSE) and clinical diagnosis [1]. Breast cancer accounts for $16 \%$ of cancer deaths in adult

\footnotetext{
* Correspondence: imugisha@ymail.com

${ }^{1}$ Institute of Allied Health Sciences, International Health Sciences University,

P.O Box 7782, Kampala, Uganda

Full list of author information is available at the end of the article
}

women, and is regarded as a major life threat requiring prompt intervention [2]. Although multifactorial, the high burden of breast cancer is ascribed to its invasive and aggressive nature, and being associated with late presentation to a health facility when it has reached advance stages. Further, the condition is intricated by the fact that its onset is often mistaken for other infections and mismanaged at that level, making it more complex and delayed interventions [5]. This as a result leads to poor prognosis $[4,6]$.

Breast cancer is preventable through the uptake of such modalities like nationwide breast cancer awareness program involving clinics in remote areas and a referral system that to improve detection and treatment $[5,7]$. This approach has been universally considered and it is hoped to subside related morbidities and 
deaths [7]. As the burden of breast cancer increases, there is minimal awareness in most parts of Africa, and this consequently hinders the possibility of cure, prevention and possible elimination $[8,9]$. As a result, this has seen unacceptably high infection cases and deaths among females $[8,10]$.

As global concerted efforts to upsurge cancer awareness and prevention, there are growing needs to explore knowledge as a measure of disease intervention and possible prevention. To this, we report on the effect of breast cancer knowledge on the adoption of breast cancer prevention modalities among women in Kyadondo County, Uganda.

\section{Methods}

\section{Design}

A household survey of women in Kyadondo County was conducted during the months of June, 2014 to August, 2015. Kyadondo County is a part of Kampala city with a proportion of the urban, peri-urban and rural set up [11]. Kyadondo County was chosen for the study because it is the area from which the Kampala cancer registry captures comprehensive data.

\section{Sampling procedures}

Cluster sampling method was used. Kyadondo County was stratified into 20 parishes [clusters] as the primary stratification variable. At this stage, each parish was further clustered into villages. Each parish comprises 10-20 villages and in each village $50-100$ households and the 20 parishes were used as the large clusters from which 10 villages were selected. At the household level, 40 households from each village and one respondent each household was selected randomly giving 400 respondents. Each household had 1-4 women who were aged 18 years of age and above. To minimize bias, 1 woman aged 18 years and above was selected from each household. The age of 18 years was chosen because it is the age of consent and that the person has insight to develop attitudes based on knowledge that may influence her practices.

Inclusion criteria: Women 18 years and above who were able to understand and communicate were included in the study. Only subjects of a sound mind, who were able to hear and speak English and Luganda (a local language used in the area).

Exclusion criteria: participants unable to understand and communicate in English or Luganda or those who declined to consent.

\section{Data collection and management}

Data was captured using a survey questionnaire that was developed from the existing literature on the topic. This was composed in English and then translated to vernacular (Luganda) after being piloted by research assistants. The questionnaire was pre-tested by research assistants among thirty women in Kisugu, Nakawa division to ensure that the most accurate information was obtained and where necessary changes were made. To ensure internal validity, only completed questionnaires were adopted. The questionnaire was interviewer administered.

Study variables: Dependent variable was breast cancer prevention modalities (adopted SBE, clinic breast examination and ultra sound) and the independent variables were background characteristics, knowledge based factors and lifestyle factors.

Knowledge of breast cancer was assessed based on the questions that sought to assess women awareness of breast cancer, knew someone that had breast cancer, risk factors of breast cancer, what to do in order to reduce the risk of acquiring breast cancer, what to do to discover breast cancer early, how to check their own breasts for lumps, and those able to recognize breast cancer signs like discharge from the breast nipple, swelling of the breast among others. The quantification was done as a proportion of the total sample size.

\section{Data management}

Data was entered and analyzed using SPSS IBM version 20. A completely edited dataset was adopted and double checked for errors and corrections done. We considered breast cancer prevention modalities (adopted SBE, CBE and ultra sound) as the dependent variable and the independent variables were background characteristics, knowledge based factors and lifestyle factors. The data was analyzed at univariate, bivariate and multivariate. Variable at univariate and bivariate with a $p$ value of less than 0.05 were considered for multivariate analysis and $p$ values less than 0.05 were considered statistically significant. Only extract of the bivariate and multivariate were used for this article.

\section{Ethical considerations}

The study was approved by research ethics committee of International Health Sciences University. All respondents provided written informed consent after receiving detailed description of the study. Eligible participants were consented in privacy and no incentives were given. Anonymity of the respondents was ensured at all stages of data analysis.

\section{Results}

General characteristics of study population

Only 414 subjects were adopted in the study, (that is $85.5 \%$ of those who had consent and had complete 
questionnaires). The results show that $55.3 \%$ were below 30 years, $35.5 \%$ were $31-50$ years and only $9.2 \%$ were above 50 years. The religious affiliation revealed that 25.5\% were Muslims, 15.5\% were Seventh Day Adventists and atheists, 29.5\% were Anglican and Roman Catholic respectively. $74.4 \%$ of these women were urban dwellers, $20.8 \%$ were in semi urban areas and only $4.8 \%$ were in rural areas of Kyadondo County. However, the study findings revealed that, $36.2 \%$ compared to $63.8 \%$ had adopted breast cancer prevention modalities in Kyadondo Count. Among the background factors that were found to be significantly associated with adoption of breast cancer prevention modalities among women in Kyadondo county included: age $(p$-value $=0.049)$, religious affiliation $(\mathrm{p}$-value $=0.054)$, level of education ( $\mathrm{p}$-value $=0.000)$ and place of residence $(\mathrm{p}$-value $=0.001)$. Others background characteristics of the women in Kyadondo County such as distance to the health facility, type of health facility and source of breast cancer information were not significantly associated with the adoption of breast cancer prevention modalities. Only the results that were found to be significantly associated with the adoption of breast cancer prevention modalities are documented in Table 1.

Table 1 Background factors associated with adoption of breast cancer prevention modalities among women in Kyadondo County $(n=414)$

\begin{tabular}{|c|c|c|c|c|}
\hline \multicolumn{5}{|c|}{ Breast cancer prevention modalities } \\
\hline Characteristics & $\begin{array}{l}\text { Adopted } \\
(n=150)\end{array}$ & $\begin{array}{l}\text { Did not adopt } \\
(n=264)\end{array}$ & Total & $p$-value \\
\hline \multicolumn{5}{|l|}{ Age } \\
\hline$<30$ years & $94(62.7)$ & 135(51.1) & 229 & \multirow[t]{3}{*}{$0.049^{*}$} \\
\hline $31-50$ years & $42(28.0)$ & 105(39.8) & 147 & \\
\hline$>50$ years & $14(9.3)$ & $24(9.1)$ & 38 & \\
\hline \multicolumn{5}{|l|}{ Religion } \\
\hline Anglican & $40(26.7)$ & $82(31.1)$ & 122 & \multirow[t]{4}{*}{$0.054^{*}$} \\
\hline Roman catholic & $54(36.0)$ & $68(25.8)$ & 122 & \\
\hline Muslim & $40(26.7)$ & $66(25.0)$ & 106 & \\
\hline Others(SDA etc) & $16(10.7)$ & $48(18.2)$ & 64 & \\
\hline \multicolumn{5}{|l|}{ Level of education } \\
\hline None & $10(6.6)$ & $42(15.9)$ & 52 & \multirow[t]{4}{*}{$0.000^{*}$} \\
\hline Primary & $36(24.0)$ & $126(47.7)$ & 162 & \\
\hline Secondary & $52(34.7)$ & $72(27.3)$ & 124 & \\
\hline Tertiary & $52(34.7)$ & $24(.1)$ & 76 & \\
\hline \multicolumn{5}{|l|}{ Place or residence } \\
\hline Urban & 120(80.0) & 246(93.2) & 366 & \multirow[t]{3}{*}{$0.024^{*}$} \\
\hline Semi urban & 28(18.7) & $8(3.0)$ & 36 & \\
\hline Rural & $2(1.3)$ & 10(3.8) & 12 & \\
\hline
\end{tabular}

*Indicates a $p$-value with a statistical significance

\section{Breast cancer knowledge of study participants}

The study findings indicate that $91.8 \%$ of the women were aware of breast cancer, $44.2 \%$ knew someone that had breast cancer, only $30.4 \%$ knew what increases the chances of breast cancer, $30.4 \%$ of the women knew what to do in order to reduce the risk of acquiring breast cancer, more than half $57.5 \%$ knew what to do to discover breast cancer early (that is by going for regular check-ups), 35.2\% knew how to check their own breasts for lumps, $32.9 \%$ of the women had been examined by a health worker and $2.4 \%$ had done an ultra sound or had a mammography done prior to the study. In addition, more than half $(56.0 \%)$ were able to recognize breast cancer signs like discharge from the breast nipple, swelling of the breast among others. The study revealed that $65.7 \%$ of the women knew where to obtain breast cancer treatment services in Kampala.

Table 2 indicates the knowledge based factors associated with the uptake of breast cancer prevention modalities among women in Kyadondo County. These include: awareness of breast cancer $(p$-value $=0.001)$, knowing someone who had suffered from breast cancer ( $p$-value $=0.000$ ), obtaining information through health talk shows on radio/television (TV) programs $(p=0.004)$, obtaining information from the health facility $(p=0.018)$, knowing that as one grew older it increased the chances of breast cancer $(p=0.000)$, having a family member that had breast cancer $(p=0.003)$, being obese $(p=0.000)$, eating lots of fatty foods $(p=0.000)$, not giving birth before 35 years (0.005), knowing what would increase one's chance of acquiring breast cancer $(p$-value $=0.000)$, knowing how to prevent breast cancer ( $p$-value $=0.000$ ), breast cancer preventions methods like doing exercises daily to control weight $(p=0.009)$, reducing weight if one is obese $(p=0.031)$, eating lots of fruits $(p=0.000)$, reducing alcohol consumption $(\mathrm{p}=0.000)$ avoiding exposure to radiation $(p=0.001)$, knowing how to check for signs and symptoms of breast cancer $(p$-value $=0.000)$, knowing what to do (for instance a clinical breast exam) $(p=0.006)$, having a breast ultra sound done $(p=0.004)$, having a mammography done $(p=0.004)$, ability to tell the different signs of cancer $(p$-value $=0.000)$ which included whole breast swelling $(p=0.002)$, swelling in the arm pit $(p=0.000)$ and having an abnormal discharge from the nipple $(p=0.000)$, and knowing where to seek breast cancer treatment services $(p=0.000)$ and at the health care facility $(p=0.002)$.

\section{Association between knowledge and uptake of breast cancer prevention practices}

In order to determine factors that jointly influenced uptake of breast cancer prevention modalities, a binary logistic regression model was fitted. The dependent 
Table 2 Knowledge based factors associated with the adoption of breast cancer prevention modalities

\begin{tabular}{|c|c|c|c|c|}
\hline \multirow[b]{2}{*}{ Variable } & \multicolumn{3}{|c|}{ Breast cancer prevention modalities } & \multirow[b]{2}{*}{$p$-value } \\
\hline & Adopted $(n=150)$ & Did not adopt $(n=264)$ & Total & \\
\hline \multicolumn{5}{|l|}{ Awareness of breast cancer } \\
\hline Yes & 147(98.0) & 233(88.3) & 380 & \multirow[t]{2}{*}{$0.001^{*}$} \\
\hline No & $3(2.0)$ & $31(11.7)$ & 34 & \\
\hline \multicolumn{5}{|l|}{ Heard of breast cancer from } \\
\hline Someone & $59(39.3)$ & 117(44.3) & 176 & 0.324 \\
\hline Radio/TV & $90(60.0)$ & $120(45.5)$ & 210 & $0.004^{*}$ \\
\hline At a health facility/hospital & $52(34.7)$ & $63(23.9)$ & 115 & $0.018^{*}$ \\
\hline From an outreach & $14(9.3)$ & $19(7.2)$ & 33 & 0.563 \\
\hline \multicolumn{5}{|l|}{ Knowing someone with breast cancer } \\
\hline Yes & $85(56.7)$ & $98(37.1)$ & 183 & \multirow[t]{2}{*}{$0.000^{*}$} \\
\hline No & $65(43.3)$ & 166(62.9) & 231 & \\
\hline \multicolumn{5}{|l|}{ Knowing what can increase chances of breast cancer } \\
\hline Yes & $80(53.3)$ & $67(25.4)$ & 147 & \multirow[t]{2}{*}{$0.000^{*}$} \\
\hline No & $70(46.7)$ & 197(74.6) & 267 & \\
\hline \multicolumn{5}{|c|}{ Which of the following can increase someone's chances of acquiring breast cancer? } \\
\hline Growing old & $22(14.7)$ & $6(2.3)$ & 28 & $0.000^{*}$ \\
\hline Having had someone who suffered from breast cancer & 24(16.0) & 18(6.8) & 42 & $0.003^{*}$ \\
\hline Having suffered breast cancer before & $10(6.7)$ & 10(3.8) & 20 & 0.189 \\
\hline Being obese & $12(8.0)$ & $0(0.0)$ & 12 & 0.000 \\
\hline Eating a lot of fatty food & $28(18.7)$ & 10(3.8) & 35 & 0.000 \\
\hline Not giving birth before 35 years & $10(6.7)$ & $4(1.5)$ & 14 & $0.005^{*}$ \\
\hline \multicolumn{5}{|l|}{ Knowing what to do to reduce chances of breast cancer } \\
\hline Yes & $78(52.0)$ & $48(18.2)$ & 126 & \multirow[t]{2}{*}{$0.000^{*}$} \\
\hline No & $72(48.0)$ & 216(81.8) & 288 & \\
\hline \multicolumn{5}{|l|}{ Reducing chances of developing breast cancer } \\
\hline Doing physical activity/exercise & $22(14.7)$ & $18(6.8)$ & 40 & $0.009^{*}$ \\
\hline Reducing weight & $14(9.3)$ & $10(3.4)$ & 24 & $0.031^{*}$ \\
\hline Eating fruits & 18(12.0) & $6(2.3)$ & 24 & $0.000^{*}$ \\
\hline Reducing alcohol consumption & $22(14.7)$ & 10(3.8) & 32 & $0.000^{*}$ \\
\hline Avoiding exposure to radiation & $12(8.0)$ & $4(1.5)$ & 16 & $0.001^{*}$ \\
\hline \multicolumn{5}{|l|}{ Know what to do to discover breast cancer early } \\
\hline Yes & 140(93.3) & $98(37.1)$ & 238 & \multirow[t]{2}{*}{$0.000^{*}$} \\
\hline No & $10(6.7)$ & 166(62.9) & 176 & \\
\hline \multicolumn{5}{|l|}{ How to check for signs of breast cancer early } \\
\hline Check her/his own breasts & 102(68.0) & $44(16.7)$ & 146 & 0.000 \\
\hline Be checked by a health worker & $62(41.3)$ & $74(28.0)$ & 136 & $0.006^{*}$ \\
\hline Have a breast ultra sound scan was done & $8(5.3)$ & $2(0.8)$ & 10 & $0.004^{*}$ \\
\hline Have a mammography done & $8(5.3)$ & $2(0.8)$ & 10 & $0.004^{*}$ \\
\hline \multicolumn{5}{|l|}{ Able to tell breast cancer signs } \\
\hline Yes & 120(80.0) & $112(42.4)$ & 232 & \multirow[t]{2}{*}{$0.000^{*}$} \\
\hline No & $30(20.0)$ & 152(57.6) & 182 & \\
\hline \multicolumn{5}{|l|}{ What shows that one has breast cancer } \\
\hline Swelling in the breast & $84(56.0)$ & $50(18.9)$ & 134 & 0.000 \\
\hline
\end{tabular}


Table 2 Knowledge based factors associated with the adoption of breast cancer prevention modalities (Continued)

\begin{tabular}{|c|c|c|c|c|}
\hline \multirow[b]{2}{*}{ Variable } & \multicolumn{3}{|c|}{ Breast cancer prevention modalities } & \multirow[b]{2}{*}{$p$-value } \\
\hline & Adopted $(n=150)$ & Did not adopt $(n=264)$ & Total & \\
\hline Whole breast swelling & $34(22.7)$ & $30(11.4)$ & 64 & $0.002^{*}$ \\
\hline Swelling in the arm pit & $14(9.3)$ & $2(0.8)$ & 16 & $0.000^{*}$ \\
\hline Discharge from the breast nipple & 20(13.3) & $8(3.0)$ & 28 & $0.000^{*}$ \\
\hline Breast pain & $28(18.7)$ & $38(14.4)$ & 66 & 0.254 \\
\hline \multicolumn{5}{|l|}{ How to check for Breast cancer signs } \\
\hline By someone checking her/his own breasts & $32(21.3)$ & 10(3.8) & 42 & 0.000 \\
\hline By health care worker examining breasts & $64(42.7)$ & $88(33.3)$ & 152 & 0.058 \\
\hline By doing a biopsy & $44(29.3)$ & $34(12.9)$ & 78 & $0.000^{*}$ \\
\hline Don't know what to do & $38(25.3)$ & $106(40.2)$ & 144 & $0.002^{*}$ \\
\hline \multicolumn{5}{|l|}{ Knew that Breast Cancer can be treated } \\
\hline Yes & $120(80.0)$ & 152(57.6) & 272 & $0.000^{*}$ \\
\hline No & $30(20.0)$ & $112(42.4)$ & 142 & \\
\hline \multicolumn{5}{|l|}{ Where $B C$ treatment can be obtained } \\
\hline Health facility & 118(78.7) & $170(64.4)$ & 288 & $0.002^{*}$ \\
\hline Herbalist & $8(5.3)$ & $16(6.1)$ & 24 & 0.761 \\
\hline Healing Centre/prayer place & $4(2.7)$ & $8(3.0)$ & 12 & 0.832 \\
\hline Don't know & $2(1.3)$ & $14(5.3)$ & 16 & $0.044^{*}$ \\
\hline
\end{tabular}

"Statistically significant $p<.05$

variable was regressed with a set of independent variables including: socio-demographic characteristics and knowledge base factors. The dependent variable was dichotomous and grouped as 1-adopted and 2-did not adopt. The results in Table 3 indicate that subjects who had primary level of education were 5 times and those with secondary education were 3 times more likely to adopt breast cancer prevention modalities respectively. The respondents who were aware of breast cancer were 1.5 times more likely to adopt breast cancer prevention modalities than their counterparts. The study findings revealed that the following increased the chances of acquiring breast cancer: ageing (OR 2.2, CI .53-9.59), having someone in the family with a history of cancer (OR 1.20, CI .31-5.07), eating fatty foods (OR 0.25, CI .06-1.09), drinking alcohol (OR 1.1, CI .33-4.08). It was also established that knowing what to do reduced the risk of breast cancer (OR 2.16, CI .92-5.07). When asked to identify what actually reduces risk of acquiring breast cancer, the women in Kyadondo identified the following: eating plenty of fruits (OR $0.10, \mathrm{CI} .01-.85$ ), reducing alcoholic consumption (OR 0.19, CI .05-.78) and avoiding exposure to radiation (OR 0.47, CI .05-4.39). The respondents who knew what to do to reduce their chances of acquiring breast cancer were 2.15 times more likely to adopt breast cancer prevention modalities.

A woman's knowledge on the signs of breast cancer was analyzed in relation to adoption to breast cancer prevention modalities. The breast cancer signs identified include: small swelling on the breast (OR 0.35, 95\% CI .15-.82), swollen breast (OR 1.39, 95\% CI 48-4.01) and abnormal nipple discharge (OR 0.27, 95\% CI .07-1.01), However it was established that the women in Kyadondo who were able to identify the signs of breast cancer were 0.61 times less likely to adopt breast cancer prevention modalities than their counterparts. When asked what can be done to discover breast cancer early: the women were able to identify the following: self-breast examination (OR 0.24, 95\% CI .07-.90), clinical breast examination (OR 0.70, 95\% CI .22-2.18), doing a biopsy (OR 0.62, 95\% CI .17-2.26), and those who did not know what to do (OR 0.73, 95\% CI .21-2.48). Finally, our respondents indicated that breast cancer treatment facilities were likely to adopt prevention modalities (OR 1.92, 95\% CI .74-4.99). The results revealed that women who acknowledged that there was breast cancer treatment at the health facility were 0.73 times less likely to adopt breast cancer prevention modalities than their counterparts.

\section{Discussion}

Breast cancer-preventive modalities are critical for the health of women and their communities. The odds of adopting breast cancer prevention modalities were higher among women who had none formal education, primary education and secondary education than tertiary education in Kyadondo County. 
Table 3 Adoption of breast cancer prevention modalities: A summary of the findings

\begin{tabular}{|c|c|c|c|c|c|c|c|}
\hline \multirow{2}{*}{$\begin{array}{l}\text { Characteristics } \\
\text { Background factors }\end{array}$} & \multirow[b]{2}{*}{ Coefficient B } & \multirow[b]{2}{*}{ Standard Error S.E. } & \multirow[b]{2}{*}{ Wald } & \multirow[b]{2}{*}{ Sig. } & \multirow[b]{2}{*}{ OR $\operatorname{Exp}(B)$} & \multicolumn{2}{|c|}{ 95\% C.I. for EXP(B) } \\
\hline & & & & & & Lower & Upper \\
\hline \multicolumn{8}{|l|}{$\overline{\text { Age }}$} \\
\hline$<30$ years & .276 & .701 & .155 & .693 & 1.32 & .33 & 5.21 \\
\hline $31-50$ years & .297 & .665 & .200 & .655 & 1.35 & .37 & 4.96 \\
\hline \multicolumn{8}{|l|}{ Religion } \\
\hline Anglican & -.094 & .557 & .029 & .865 & .91 & .31 & 2.71 \\
\hline Roman catholic & -.309 & .567 & .298 & .585 & .73 & .24 & 2.23 \\
\hline Muslim & -.152 & .546 & .077 & .781 & .86 & .30 & 2.50 \\
\hline Education & & & 11.310 & .010 & & & \\
\hline None & 1.043 & .619 & 2.837 & .092 & 2.84 & .84 & 9.55 \\
\hline Primary & 1.710 & .516 & 10.960 & .001 & 5.53 & 2.01 & 15.21 \\
\hline Secondary & 1.322 & .505 & 6.862 & .009 & 3.75 & 1.40 & 10.09 \\
\hline Residence & & & 8.309 & .016 & & & \\
\hline Urban & -2.095 & 1.146 & 3.342 & .068 & .12 & .01 & 1.16 \\
\hline Semi urban & -.887 & 1.145 & 600 & .438 & .41 & .04 & 3.88 \\
\hline \multicolumn{8}{|l|}{ Knowledge base factors } \\
\hline Heard of Breast Cancer (yes) & .437 & .868 & .254 & .614 & 1.55 & .28 & 8.49 \\
\hline Told by someone (yes) & -.051 & .377 & .018 & .893 & .95 & .45 & 1.99 \\
\hline Health facility (yes) & .075 & .398 & .035 & .851 & 1.08 & .49 & 2.35 \\
\hline Knew someone with $\mathrm{BC}($ yes) & -.071 & .341 & .043 & .835 & .93 & .48 & 1.82 \\
\hline Risk of breast cancer & -1.080 & .393 & 7.547 & .006 & .34 & .16 & .73 \\
\hline Growing old(yes) & .814 & .738 & 1.214 & .271 & 2.26 & .53 & 9.59 \\
\hline Family history of $\mathrm{BC}($ yes) & .218 & .716 & .093 & .760 & 1.24 & .31 & 5.07 \\
\hline Eating fatty foods(yes) & -1.389 & .750 & 3.424 & .064 & .25 & .06 & 1.09 \\
\hline Drinking alcohol (yes) & .141 & .645 & .048 & .827 & 1.15 & .33 & 4.08 \\
\hline Know how to reduce chances of $\mathrm{BC}(\mathrm{yes})$ & .769 & .436 & 3.115 & .078 & 2.16 & .92 & 5.07 \\
\hline Eating fruits (yes) & -2.280 & 1.080 & 4.461 & .035 & .10 & .01 & .85 \\
\hline Reduce alcohol intake (yes) & -1.650 & .716 & 5.308 & .021 & .19 & .05 & .78 \\
\hline Avoid radiation (yes) & -.748 & 1.136 & .434 & .510 & .47 & .05 & 4.39 \\
\hline Know how to check for signs of $\mathrm{BC}(\mathrm{yes})$ & -3.719 & .509 & 53.428 & .000 & .02 & .01 & .07 \\
\hline Clinical breast examination (yes) & .913 & .355 & 6.625 & .010 & 2.49 & 1.24 & 4.10 \\
\hline Have breast ultra sound (yes) & .894 & 1.671 & .286 & .593 & 2.45 & .09 & 64.68 \\
\hline Have a mammogram done (yes) & .172 & 1.173 & .021 & .884 & 1.19 & .12 & 11.82 \\
\hline Know all signs of $\mathrm{BC}($ yes) & -.486 & .475 & 1.048 & .306 & .62 & .24 & 1.56 \\
\hline Small swelling on the breast (yes) & -1.039 & .430 & 5.854 & .016 & .35 & .15 & .82 \\
\hline Swollen breast (yes) & .328 & .542 & .366 & .545 & 1.39 & .48 & 4.01 \\
\hline Abnormal nipple discharge (yes) & -1.295 & .708 & 3.345 & .067 & .27 & .07 & 1.10 \\
\hline Self breast examination (yes) & -1.423 & .671 & 4.494 & .034 & .24 & .07 & .90 \\
\hline Examined by a Clinician (yes) & -.361 & .583 & .383 & .536 & .70 & .22 & 2.18 \\
\hline Doing a biopsy (yes) & -.478 & .660 & .525 & .469 & 62 & .17 & 2.26 \\
\hline Don't know what to do & -.320 & .625 & .261 & .609 & .73 & .21 & 2.48 \\
\hline Availability of BC treatment (yes) & .653 & .487 & 1.799 & .180 & 1.92 & .74 & 4.99 \\
\hline Provided at the health facility (yes) & -.303 & .459 & .435 & .510 & .74 & .30 & 1.82 \\
\hline Constant & 4.424 & 1.686 & 6.887 & .009 & 83.45 & & \\
\hline
\end{tabular}

-2 Log likelihood 294.388

Cox \& Snell $R^{2} 0.450$

Nagelkerke $R^{2} 0.617$ 
The odds of adopting breast cancer prevention modalities were more likely for a woman who had general knowledge on breast cancer than if she did not. This is similar to what was revealed in a study of women's knowledge toward breast cancer that established that the respondents who had little or no preventive breast cancer information were less likely to know how to prevent breast cancer [11]. The study results established that chance of a woman adopting breast cancer prevention modalities were less if she heard it from someone in the community. There were moderate chances of a woman in Kyadondo county adopting breast cancer prevention modalities if she went to the health facility to get information on breast cancer.

The odds of a woman adopting breast cancer prevention modalities were less likely if she knew someone who had suffered from breast cancer. This is an indicator of a deficit in the knowledge of breast cancer which is in line with the findings on breast cancer screening practices among Ghanaian women where higher knowledge was linked to better management ( $\mathrm{rs}=0.316$, $N=465, p<0.001)$ [7].

The odds of adopting breast cancer prevention modalities were higher for a woman who was growing older than their younger counterparts. The chances of a woman in Kyadondo county adopting breast cancer prevention modalities were moderate among women with a family history of the disease.

Knight in his study on breast cancer reported that the consumption of alcohol in large quantities increases the risk of developing breast cancer [10]. Further, a study conducted by Merriman argues that women who do not have children or who had their first child after age 30 have a slightly higher breast cancer risk of acquiring breast cancer [8]. The findings also revealed that the odds of adopting breast cancer prevention modalities were higher for a woman who knows what reduces the chances of acquiring breast cancer. This means a woman is likely to take precaution against breast cancer if she knew the benefits of exercising, reducing weight, eating fruits, reducing alcoholic consumption and avoiding exposure to radiation. Ahmadian upholds this by advising adults to eat healthy foods, take a glass of wine occasionally, exercising like having a 25 min' walk every day or have at least $150 \mathrm{~min}$ a week of moderate aerobic activity [12].

The study indicates that the odd of adopting breast cancer prevention modalities were higher if a woman had knowledge on the signs of breast cancer than if she did not. The odds of adopting breast cancer prevention modalities were higher for a woman who knew what to do to discover breast cancer early (self-breast examination, clinical examination, breast ultra sound and mammography) than for someone who did not. Merriman observed that women with a better knowledge level on breast cancer (Adjusted Odds 2.5) where more likely to adopt BSE [8].

The results revealed a strong relationship between adopting breast cancer prevention modalities and exercising. This means that the more a woman exercises the lower the chances of her acquiring breast cancer. Lemanne provides evidence of the benefits of exercising that included: improves cardiovascular (heart and circulation) fitness and that exercise helps one gain a healthy weight; made the muscles stronger; reduces fatigue and helps people have more energy; helps lower anxiety and depression; makes one feel happier and be better about oneself as well as long term effects of reducing breast cancer [13].

The odds of adopting breast cancer prevention modalities was more likely if a woman was able to identify signs of cancer like a small swelling on the breast than if she did not. It was established that women who had a strange discharge from the breast may signify cancer were 8 times more likely to adopt breast cancer prevention modalities than if they were not. This concurs with Merriman who argues BSE is a patient-centred, noninvasive screening procedure that allows women to routinely check their bodies [8]. In addition the odds of adopting breast cancer prevention modalities were more likely if a woman was able to examine her breast than if she did not. The women who acknowledged that there is treatment of breast cancer had higher chances of adopting breast cancer prevention modalities than their counterparts. This affirms the findings among female undergraduate students in Buea where a gap in knowledge was established in the practice BSE in the prevention of breast cancer [14]. Therefore this study is in agreement with what Fon already reported that acquiring cancer knowledge, cancer detection and treatment among women increases women's practice of BSE [7]. This may enable a woman to make an informed decision about breast cancer screening risks and the benefits.

Although our findings are factual, it falls short of the following; a) being a field based survey, our findings solely relied on the respondents have given us accurate information; otherwise the study did not have a confirmatory basis to validate the trueness of their responses. b) this study could have been subjective to forms of bias particularly recall bias, in addition, since we used an intervieweradministered questionnaire, it is likely that interviewer bias was encountered, c) since our study targeted a single adult female respond as a proxy to each household, it is likely some selection bias was encountered.

\section{Conclusion}

Breast cancer awareness ought to be rolled out particularly to the school girls with emphasis on how to conduct breast self-examination and where to obtain a 
clinical breast exam so as to minimize late breast cancer detection and treatment at stage 4 . In addition, health programs in form of the media coverage through newspapers, local written and oral, radio and television could alleviate breast cancer awareness. Through these, it is hoped to harness awareness of breast cancer, the need of its early diagnosis, as well as prompt treatment.

\section{Abbreviations}

BCE: Breast clinical examination; BSE: Breast self-examination; OR: Odds Ratio

\section{Acknowledgements}

The authors express our utmost gratitude to our respondents who voluntarily responded to our questionnaire. We are grateful to research assistants for the field support.

\section{Funding}

Not applicable

\section{Availability of data and materials}

We did not obtain consent to share data obtained from the questionnaire, however the datasets used and/or analyzed during the current study available from the corresponding author on reasonable request.

\section{Authors' contributions}

CA, DA, EA, SM and IMT conceived the study idea, participated in study design; data acquisition, analysis, and interpretation; and manuscript drafting and revision. CA and IMT participated in drafting data collection tools and scheduling for internal responsibilities. CA, DA, EA and SM drafted and revised the manuscript. IMT critically reviewed the manuscript. All authors read and approved the final manuscript.

\section{Ethics approval and consent to participate}

We received ethical approval from International Health Sciences University Research Ethics Committee (REC). All respondents provided written informed consent after receiving detailed description of the study. Eligible participants were consented in privacy and no incentives were given. Anonymity of the respondents was ensured at all stages of data analysis.

\section{Consent for publication}

Not applicable

\section{Competing interests}

The authors declare no conflict of interest in this work.

\section{Publisher's Note}

Springer Nature remains neutral with regard to jurisdictional claims in published maps and institutional affiliations.

\section{Author details}

'Institute of Allied Health Sciences, International Health Sciences University, P.O Box 7782, Kampala, Uganda. ${ }^{2}$ Mbarara University of Science and Technology, P.O Box 1410, Mbarara, Uganda.

Received: 2 November 2017 Accepted: 19 February 2018

Published online: 23 February 2018

\section{References}

1. Galukande M, Wabinga H, Mirembe F, Karamagi C, Asea A. Difference in risk factors for breast cancer by ER status in an indigenous African population. International Scholarly Research Notice: Oncology. 2013;10:1155.

2. Groot MT, Baltussen R, Uyl-de Groot CA, Anderson BO, Hortobagyi GN. Costs and health effects of breast cancer interventions in epidemiologically different regions of Africa, North America and Asia. Breast J. 2006;12(Suppl 1):S81-90

3. Wilson CM, Tobin S, Young RC. The exploding worldwide cancer burden: the impact of cancer on women. Int J Gynecol Cancer. 2004;14:1-11.

4. Gakwaya A, Galukande M, Luwaga A, Jombwe J, Faulal J, Kiguli-Malwadde E, et al. Breast cancer guidelines for Uganda. Afr Health Sci (2nd). 2008;8(2):126-32.
5. Semarya B, Worknish S, Mignote H, Mesfin A, Alemseged A. Assessment of knowledge of breast cancer screening methods among nurses in university hospitals in Addis Ababa, Ethiopia. International Scholarly Research Notice: Oncology. 2011:10:2013.

6. Okobia MN, Bunker CH, Okonofua FE, Osime U. Knowledge, attitude and practice of Nigerian women towards breast cancer: a cross-sectional study. World J Surg Oncol. 2006;411:1477-7819.

7. Samuel YO, Martin B, Joel Y. Knowledge attitudes, beliefs, behavior and breast cancer screening practices in Ghana, West Africa. Pan Afr Med J. 2012;11

8. Merriman A. Emerging breast cancer epidemic: impact on palliative care. Breast Cancer Res. 2010:12(suppl. 4):s11.

9. Oluwatosin OA, Oladepo O. Knowledge of breast cancer and its early detection measures among rural women in Akinyele local government area, Ibadan, Nigeria. BMC Cancer. 2006;271

10. Knight JA, Bernstein L, Largent J, Capanu M, Begg CB, Mellemkjaer L, Lynch CF, Malone KE, Reiner AS, Liang X, Haile RW, Boice JD Jr. Alcohol intake and cigarette smoking and risk of a contralateral breast cancer: the Women's environmental cancer and radiation epidemiology study. Am J Epidemiol. 2009;169(8):962-8. 10.1093/aje/kwn422

11. Christine A, Dinah A, Steven M, Elly A. The Influence of life style on the adoption of Breast Cancer Prevention Modalities among women. A case study of Kyadondo County. Journal of Health, Medicine and. Nursing. 2016;vol. 29.

12. Ahmadian M, Abu SA. Application of health behavior theories to breast cancer screening among Asian women. Asian Pac J Cancer Prev. 2013;14(7):4005-13.

13. Lemanne $D$, Cassileth $B$, Gubili J. The role of physical activity in cancer prevention, treatment, recovery and survivorship. Oncol Lett 2013;27(6):580-5.

14. Fon PN, Jules CNA, Tebit EK, Anna LN, Taddi RGT. Knowledge, attitude and practice of breast self-examination among female undergraduate students in the University of Buea. BMC Research Notes V. 2015;8
Submit your next manuscript to BioMed Central and we will help you at every step:

- We accept pre-submission inquiries

- Our selector tool helps you to find the most relevant journal

- We provide round the clock customer support

- Convenient online submission

- Thorough peer review

- Inclusion in PubMed and all major indexing services

- Maximum visibility for your research

Submit your manuscript at www.biomedcentral.com/submit
Biomed Central 